\title{
El PENSAMIENTO NO INTELECTUALISTA COMO SÍNTESIS ENTRE LA METAFÍSICA DEL ACTO Y LA METAFÍSICA DE LA REPRESENTACIÓN
}

\author{
[THE NON-INTELLECTUALIST THOUGHT AS SYTHESIS BETWEEN THE METAPHYSISCS OF ACT AND THE \\ METAPHYSICS OF REPRESENTATION]
}

\author{
Antonio Gutiérrez Pozo * \\ Universidad de Sevilla, España
}

\begin{abstract}
Resumen: La metafísica del acto define la realidad como dinamismo y ejecutividad. La metafísica de la representación concibe el ser como objeto identificado por la conciencia. Establecer un puente entre estas dos metafísicas, o en otras palabras entre diferencia e identidad, proceso y objetivación, equivale a integrar acción y pensamiento. Para conseguirlo, consideramos necesario defender la existencia de una conciencia no intelectualista ni objetivadora que posea un pensar que forme parte del propio devenir.

Palabras-Clave: acto; representación; objetivación; conciencia; pensamiento; no intelectualismo
\end{abstract}

\begin{abstract}
The metaphysics of the act defines reality as dynamism and performativeness. The metaphysics of representation conceives the being as an object identified by consciousness. Establishing a bridge between these two metaphysics, or in still other words between difference and identity, process and objectification, is equivalent to integrating action and thought. To achieve this, we consider necessary to defend the existence of a non-intellectualist and non-objectivating consciousness that possesses a thought that forms part of one's own becoming.

KEYWORDS: Act; Representation; Objectification; Consciousness; Thought; NonIntellectualism
\end{abstract}

\section{INTRODUCCIÓN}

unque la distinción entre las dos grandes tradiciones de la metafísica del acto Ay la metafísica de la representación es moderna, su relevancia histórico/filosófica es más profunda y puede remontarse al enfrentamiento entre -de manera respectiva- el aristotelismo y el platonismo. No obstante, en este trabajo nos centraremos en las versiones modernas de estas dos metafísicas, concreta y respectivamente en la filosofía fichteana de la actividad y la energía (Tathandlung) y la filosofía de la conciencia y la idea (cogito) cartesiana. Las categorías básicas que describen la metafísica del acto son evidentemente devenir, ejecutividad y diferencia, mientras que las que caracterizan a la metafísica de la representación son estatismo, cosificación e identidad. La enemistad entre estas dos metafísicas en principio es inevitable. Por una parte, cuando domina la identidad, muere la diferencia, que es homogeneizada y reducida a mera apariencia, a falsedad, pues finalmente se disuelve, rendida ante el poder de absorción de la identidad que se la identifica y se la apropia. Por otra, la afirmación radical

* Catedrático de la Facultad de Filosofía de la Universidad de Sevilla, Área de conocimiento de Estética y Teoría de las Artes.E-mail: agpozo@us.es 
de la diferencia y la contradicción -que es el máximo de la diferencia, pues la hace absoluta e irreducible- deshace cualquier posibilidad de identidad. En este caso, es la identidad la que acaba en apariencia y ficción. Por todo esto es natural que la tradición metafísica de la representación y la identidad haya sido también denominada 'metafísica de la sustancia'. Lo interesante de la 'metafísica de la representación' es que asume ese carácter sustancialista y le agrega el descubrimiento moderno de la conciencia, de modo que es ahora el pensamiento -como representar- el que identifica, objetiva y cosifica. Puede decirse entonces que equivale a una vuelta de tuerca de aquel sustancialismo platónico mediante la conciencia cartesiana representacionalista. Dado que la intención de este trabajo es plantear una hipótesis original acerca de la posibilidad de establecer un puente entre aquellas dos grandes tradiciones metafísicas, integrando identidad $\mathrm{y}$ diferencia, objetivización y proceso, podemos ahora afinar esa síntesis reclamando una mediación entre devenir o acción y conciencia o pensamiento. Más aún, precisamente es la introducción de este último elemento moderno lo que nos va a permitir justificar la existencia de aquel puente entre las dos metafísicas mediante la renovación de la idea de pensamiento. Nuestra hipótesis es que sólo una nueva forma de entender el pensamiento que caracteriza a la conciencia puede hacer posible unir aquellas dos metafísicas tradicionalmente enfrentadas.

\section{IDEALISMO DE LIBERTAD E IDEALISMO DE LA CONCIENCIA}

La metafísica del acto consiste en la afirmación realista del ser como ejecutividad o 'ponerse en obra'. Ser es realizar lo que se es, llevar a cabo su esencia, actualizarla, de manera que la metafísica del acto lo entiende todo como realidad ejecutiva o dinámica: todo es realizándose, llevándose a cabo. La expresión histórico-filosófica ejemplar de esta

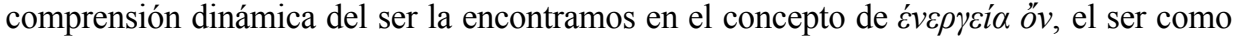
acto de Aristóteles, según el cual ser algo no es meramente mostrar una apariencia sino estar siendo -realizando- lo que se es. El ser es pues actividad autorrealizativa. La realidad es dinamismo, proceso. Esta primacía de la acción propia de la tradición dinamicista del ser ejecutivo se encuentra en Fichte, para el cual "toda realidad (Realität) es activa (tätig) y todo lo activo es realidad" (Fichte, 1794-1802, p. 134). Para Fichte la sustancia de lo real es el yo como Tathandlung, esto es, el yo como fuerza activa libre que se auto-pone frente a lo que se le resiste y lo niega, el no-yo del objeto. Esto es lo que llama Ditlhey "idealismo de la libertad (Idealismus der Freiheit)" (Dilthey, 1911, pp. 107112). Este yo fichteano es el modelo de la metafísica del acto en tanto es pura actividad que, "en tanto pone (setzt) el propio ser del yo, no se dirige a ningún objeto (Object), sino que vuelve sobre sí mismo" (Fichte, 1794-1802), p. 134). Fichte (1797a, p. 495) escribe que "el yo es originariamente (ursprünglich) sólo un actuar, un hacer (Tun)". Es tan pura acción que no se verifica en objetividad sino que retorna al yo, que es actividad y no cosa, objeto. Esta Tathandlung o acción activa es, según Fichte (1797a, p. 468), "una actividad (Tätigkeit) que no presupone un objeto sino que lo produce (hervorbringt), y donde la acción (Handeln) deviene inmediatemente acto (Tat)" 1 .

La metafísica de la representación entiende el ser como objeto identificado por la conciencia, como cogitatio. Aunque tiene su raíz en la modernidad, Heidegger enseña que este enfrentamiento entre las dos metafísicas, la dualidad ejecutividad/objetividad, se remonta a la oposición entre la $i \delta \varepsilon ́ \alpha$ (idea) platónica, que designa lo que es el ente y que acabará convirtiéndose en la representación (Vorstellung), y la ćvé $\rho \gamma \varepsilon l \alpha$ (enérgeia) aristotélica, que se refiere al hecho de que el ente es y que desembocará en la actualitas y la existentia, o sea, en la realidad efectiva (Wirklichkeit) (Heidegger, 1941, pp. 410s) ${ }^{2}$. Al apoyarse sobre la idea moderna que hace del sujeto condición de todo objeto, de modo que considera que nada se nos da sin conciencia, sin representación, la metafísica de la 
representación, base del idealismo filosófico moderno, supone la objetivación o cosificación de aquella realidad dinámica. Su origen según Henry se encuentra en la filosofía cartesiana, con su enfatización del representar de la conciencia que objetiva e identifica, y su final en la schopenhaueriana y nietzscheana, que priman la voluntad en detrimento de la representación: "La historia de la metafísica occidental deviene desde Descartes y mediante él una historia de la metafísica de la representación (métaphysique de la représentation), la cual halla su acabamiento (aboutissement) en Nietzsche" (Henry, 2012, p. 307)3. Además, añade Henry (2012, p. 307), "esta reducción del pensamiento de Descartes a una metafísica de la representación no se realiza de pasada (par un biais) ni se basa en un aspecto particular de la doctrina, sino que afecta a su centro, señala al cogito: yo pienso quiere decir yo me represento (je me représente)". Por ser una ontología de nuestra experiencia de los objetos, Henry (1985, p. 7) entiende esta metafísica de la representación como una filosofía de la conciencia que comprende la experiencia como relación del sujeto con el objeto.

Estas dos metafísicas, en tanto responden a la entronización respectiva de las categorías de devenir y conciencia, conceptos fundamentales que definen la historia de la filosofía, dan nuevos nombres más precisos a lo que habitualmente se ha denominado realismo e idealismo, un realismo dinámico y un idealismo de la conciencia o la subjetividad. En las ecuaciones que habíamos planteado hasta ahora entre identidad, diferencia y devenir, faltaba la noción moderna fundamental de conciencia. La introducción de la conciencia por parte de la metafísica de la representación supone la objetivación de lo real dinámico, pues la conciencia, al representar, identifica, objetiva lo procesual. Para la filosofía de la conciencia todo lo existente tiene como condición el que podamos representárnoslo, de modo que ser conocido y ser un fenómeno significa ser representado. De aquí deduce Henry (1985, p. 125) que "ser objeto es ser representado (être représenté), y ser representado es ser conocido (être connu)", es decir, que "la representatividad (représentativité) es la esencia común del conocimiento y del objeto en tanto que esencia común del fenómeno (phénomène) y del ser". La conciencia piensa representativamente, o sea, objetivando y paralizando, reduciendo a identidad. Esta metafísica, al insistir en la representación, detiene y cosifica lo que era puro dinamismo, y este es el significado de la natura naturata spinoziana, los productos en que se objetiva y fosiliza la energía creativa de la natura naturans (Spinoza, 1677, II, xxix, Schol, p. 101). En suma, la oposición entre estas dos metafísicas equivale a la tensión entre el idealismo de la conciencia del ego cogito cartesiano como modelo de la representación y el idealismo de la libertad de la Tathandlung fichteana, que es pura energía y modelo de actividad libre; una tensión entre conciencia objetivadora y Tathandlung, cosificación y energía.

\section{LA IRREPRESENTABILIDAD DEL ACTO}

El problema de la metafísica de la representación reside en la imposibilidad de objetivar -representar- el acto, lo ejecutivo, el ser en definitiva en tanto es un 'ponerse en obra', pues en cuanto lo objetivamos pierde ipso facto su realidad ejecutiva, se cosifica, paraliza y deja de ser en acto. Pierde en suma su realidad. La mediación que perseguimos entre conciencia/acto, idea/energía, cosificación/actividad, se antoja entonces complicada porque el acto como tal es irrepresentable, inobjetivable. Aquella imposibilidad se encuentra ya en Fichte (1797b, p. 531), para el que "la actividad es agilidad (Agilität), movimiento interno (innere Bewegung)", o sea, en ejecutarse, un hacerse por dentro o serse, pero este ser como agilidad o energía ejecutiva "no se deja contemplar de otro modo", pues en cuanto tal agilidad es inobjetivable. Por ello, el yo, que es actividad según Fichte (1794, p. 296), no puede ser objetivado en tanto que tal, positivamente, de modo 
que "el yo puro (reine Ich) sólo puede ser representado negativamente (negativ), como lo contrario del no-yo (Gegenteil des Nicht-Ich)"4. El yo-acto o yo-Tathandlung es tan irrepresentable directamente que sólo se lo puede representar indirectamente afirmando que es lo contrario de lo que no es él. Recordemos que Schopenhauer, primero, asumió la dialéctica metafísica del acto/metafísica de la representación bajo el esquema dualista voluntad/representación, y, segundo, estableció la diferencia e inadecuación radical entre ambos órdenes metafísicos. Para Schopenhauer $(1819, \S 21$, p. 170), "toda representación (Vorstellung), sea del tipo que sea, todo objeto (Objekt), es manifestación, fenómeno (Erscheinung)", mientras que "la cosa en sí (Ding an sich) es sólo la voluntad (Wille)". Todo lo que hay, todo lo que se nos aparece, es para Schopenhauer $(1819, \S 22$, p. 171) efectivamente objetivación de la voluntad y ésta no tiene otra forma de aparecer que objetivándose en los objetos, pero la voluntad misma, "esta cosa en sí como tal nunca es objeto". Contra la primacía otorgada por Descartes al representar y la idea, Schopenhauer considera que no se puede explicar el mundo sólo a base de representación porque ésta no puede acceder al ser sino sólo al fenómeno, a lo que aparece, al lado exterior de la esencia o cosa en sí, que es la voluntad y que consiste en acción, en vida.

La verdad no es la idea o representación de lo vivido sino vivirlo, ejecutarlo, serlo por dentro. La objetivación que supone el representar sólo ve por fuera el ejecutarse de la voluntad, que es lo esencial. Este desajuste radical entre el 'fuera' (objetivación) y el 'dentro' (voluntad) supone la devaluación de la representación ya que en ella, como consecuencia de su naturaleza objetivante, no hay nada de realidad, puesto que ésta, una vez representada, queda vacía de su efectividad y reducida a su propia sombra o esquema. El problema de la metafísica de la representación -que según Heidegger se configuró ya en Platón- reside en que se funda sobre la estructura sujeto-objeto, según la cual el sujeto no puede pensar sino representando u objetivando, es decir, poniendo ante sí lo real en conceptos: "Pensar (Denken) es representar (Vorstellen) algo en general, o sea, en conceptos (Begriffen)", y "re-presentar (Vor-stellen) significa traer (bringen) y tener algo ante sí, tener presente (präsent haben) algo ante sí como sujeto (Subjekt)" (Heidegger, 1935-36, p. 139). Decir que este pensar representacional es subjetivista equivale a sostener que es objetivador o conceptualizador. Heidegger confirma que este pensar como representar es "un cierto modo de pensar que falsifica (verfälscht) siempre y necesariamente lo real (Wirkliche) en la medida en que todo representar detiene (still stellt) el insuspendible devenir (unausgesetzte Werden), y con lo así fijado (Festgestellten) contra el fluyente devenir (fliessenden Werden) establece algo que no corresponde, algo incorrecto, erróneo (Irriges) como lo supuestamente real (angebliche Wirkliche)" (Heidegger, 1931-40, p. 233). Al pensar algo, la metafísica de la representación lo falsea, pues sustituye su realidad, su verdad dinámica y efectiva, por un objeto, el concepto de aquel ser ejecutivo. La representación de algo equivale a eso mismo pero ya desrealizado, espectralizado. De hecho, la energeía ón aristotélica, el ser en acto, no implica presencia para sí sino que es pura ejecución o posición sin autoconciencia, de modo que al convertirla en objeto, en 'ser para', deja ya de ser ella en su puro llevarse a cabo. El ser en acto es realizativo, ejecutivo y no reflexivo.

Aquella imposibilidad de objetivar el acto se funda, pues, sobre la aparente oposición inconciliable entre la metafísica del acto y la de la representación, entre el 'ser en sí y el 'ser para sí', la realización o verificación y la objetivación. Lo que define a la acción es, en palabras de Ricoeur (1950, p. 191), "el carácter de presente (présent) y de lleno (plein)", de modo que cualquier acción "está más allá de toda anticipación, de todo proyecto. Ya no es una palabra (parole), un Logos, es un acto entretejido en la plenitud de lo real. La acción es el acontecimiento (événement) mismo". Por eso, es irrepresentable como tal, inobjetivable. La propia palabra que la describe, 'acción', ya no es la acción. Hay una distancia insalvable entre la acción como acontecer y cualquier representación de la acción, que ya no sería propiamente acción. El primado moderno de la representación 
subjetiva de la conciencia se enfrentaría a la actualidad. Esta incompatibilidad entre la metafísica de la representación y el devenir, que queda incluso ahogado y reprimido por aquélla, ha sido destacada por Deleuze (1968, pp. 19, 32), quien sostiene que "el movimiento (mouvement) se opone al concepto y a la representación", de manera que "en el orden dinámico (ordre dynamique) no hay ni concepto representativo (concept représentatif) ni figura representada".

\section{VIDA INOBJETIVABLE}

La manifestación más clara del ser ejecutivo de que disponemos es nuestro propio vivir. Entendido el concepto 'ser' desde la cosificadora y objetivadora perspectiva platónica, es natural que Heimsoeth (1922, pp. 131-171) proponga que la oposición central que atraviesa la filosofía occidental es la que se establece precisamente entre ser -lo estático- y vida -lo dinámico. En clave antiplatónica, no es casual que encontremos esa tesis del ser como vida expuesta ya por Fichte (1805, p. 361), el filósofo de la Agilität: "El ser simple y absolutamente como ser es viviente (lebendig) y activo (tätig) en sí mismo, y no hay otro ser que la vida (Leben)". Nietzsche disolverá toda cosificación propia del pensar representacional -que llama platonismo- al enseñar que ser es vivir: "El ser -no tenemos otra representación (Vorstellung) de él más que vivir (leben). ¿Cómo puede entonces 'ser' algo muerte (etwas Todtes)" (Nietzsche, 1885-86, 2 [172], p. 153). Contra cualquier resto de objetivación metafísica, Nietzsche (1886-87, 7 [54], p. 312) afirma que el único ser es el devenir, la actividad: "Imprimir (aufzuprägen) al devenir (Werden) el carácter de ser (Charakter des Seins), esa es la más elevada voluntad de poder (Wille zur Macht)". Ahora bien, Henry (1985, p. 8) sostiene que "la vida es el ser que no ocurre (advient) nunca en tanto que objeto de un sujeto", y "la interpretación del ser como vida es el suceso (événement) crucial de la cultura moderna" porque acaba con la idea sustancialista y objetivada del ser propia de la metafísica de la representación, dominante desde Platón. La exaltación del concepto de vida en el pensamiento moderno significa recuperar la primacía de la actividad como esencia del ser, perdida por la metafísica de la representación.

Esta implantación de la idea de vida como ejecutividad encuentra en la fenomenología husserliana a la altura de 1912 un momento destacado. Husserl acomete la relación entre vida/acto y representación matizando que también el cogito, como acto de conciencia, es en principio vida, vivencia, acto. Pero entonces también la vida es un cogito, sólo que viviente. Por tanto, 'vida' es lo que llama cogito lebendig, cogito viviente, o sea, todo acto de la conciencia en actitud natural, en la actitud del vivir. En esta conciencia natural, viviente y ejecutiva en la que ha desembocado la Tathandlung fichteana que entendía el ser como Agilität, en este cogito lebendig, el yo vive en acto, ejecutando; en cada acto, el yo vive en él, sin representar lo vivido. La vida es una conciencia, un cogito, pero un cogito no representativo sino viviente, ejecutivo. En palabras de Ricoeur (1950, p. 194), es "una conciencia no representativa (conscience nonreprésentative), ni siquiera una representación práctica; es una conciencia que es acción”. La vida entonces, la conciencia ejecutiva o cogito lebendig, sólo se puede describir, como hace Husserl (1912, § 27, p. 56), mediante expresiones en primera persona (Ichrede): ando, amo, pienso, escribo, represento, etc. Husserl aclara que en estas manifestaciones primarias del cogito que constituyen la vida o actitud natural de la conciencia, es decir, "en el natural dejarse vivir (natürlichen Dahinleben), vivo (lebe) constantemente en esta forma fundamental de toda vida actual (aktuellen Lebens), enuncie o no el cogito, diríjame o no reflexivamente (reflexiv) al yo y al cogitare. Si lo hago, entra en la vida un nuevo cogito viviente (cogito lebendig), que por su parte no es reflejado (unreflektiert), o sea, no es para mí objetivado (gegenständlich)" (Husserl, 1912, § 28, p. 59). Mientras 
vivo no represento ni objetivo, y cuando represento ya no vivo lo representado, pero vivo (en) el acto de representar. Por tanto, Husserl prima la vida, pues a ella queda subordinado el acto de representar u objetivar lo vivido, ya que en tanto se ejecuta él mismo es vivencia no objetivada. La vida como tal es inobjetivable. La reflexión que vuelve sobre lo vivido, sobre el cogito lebendig, con el fin de representarlo u objetivarlo, por así decirlo, siempre llega tarde. El resultado de la actividad reflexiva ya no es lo vivido como tal sino su sombra. Lo que fue vida, acto, lo convierte la reflexión en cosa, objeto.

Por esto, afirma Ricoeur (1950, p. 195), "la reflexión duplica difícilmente el cogito no representativo (Cogito non représentatif); la reflexión tiende pues a abandonar (déserter) los modos activos de la conciencia y a entregarlos (les livrer) al proceso de objetivación, que coincide por otra parte con el espíritu científico". La reflexión no puede sensu stricto duplicar la vivencia, pues al representarla lo que obtiene ya no es la vivencia en su ejecutarse sino la vivencia desvivida, objetivada, reducida a su sombra esquemática. La reflexión, como actividad representacional, objetiva. El amor como vida, vivir el amor, p. e., es amar, justo lo contrario de convertir ese amor en objeto para un sujeto. Objetivarlo o representarlo es ya no vivirlo. Al detener su realidad vivida y objetivarlo, al dejar de amar, pierde su realidad ejecutiva amorosa. Si la vida es la inmediatez del ser en acto, la presencia inmediata del llevarse a cabo algo sin restricciones, la representación significa su detención y mediación. Por eso Deleuze (1968, p. 29) escribe que "la representación mediatiza (médiatise) lo vivido (vécu) al relacionarlo con la forma de un objeto idéntico o semejante (semblable)". La representación es mediación frente a la inmediatez del vivir. Cuando vivo un dolor o cuando ando p. e., en general, en cualquier vivencia en tanto es vivida, verificada, no hay mediación posible, sino que estoy inmediatamente metido en el acto, viviéndolo, ejecutándolo, siéndolo. La mediación que implica la representación tiene como consecuencia que lo vivido en tanto representado ya no es lo vivido sino justo lo contrario: algo objetivado. Sólo nos queda advertir que esta relación entre el acto y la representación no es ajena al binomio identidad/diferencia. La representación, en tanto objetivar, identifica. Por eso Deleuze $(1968$, p. 1) ha escrito que "el primado de la identidad (primat de l'identité), en cualquier forma que sea entendido, define el mundo de la representación". Al contrario, en el ámbito del ser ejecutivo, del acto, reina la diferencia, pues en él las cosas van siendo y des-siendo. La objetivación que lleva consigo el representar significa entonces la supresión de la diferencia en favor de la identidad. En efecto, según Deleuze (1968, p. 303), "la diferencia es invertida (renversée) ante todo por las exigencias de la representación que la subordina a la identidad".

\section{HEIDEGGER Y LA ONTOLOGÍA PRERREFLEXIVA DE LA CAMPESINA}

Este problema encuentra una expresión muy esclarecedora en la obra de Heidegger. En Sein und Zeit nos indica que el ser del martillo, su verdad, reside en el martillar: "El martillar (Hämmern) mismo descubre (entdeckt) la manejabilidad (Handlichkeit) específica del martillo" (Heidegger, 1927, § 15, p. 93). Más tarde, precisa que la verdad de cualquier útil está en su actuar como tal, en su servicialidad o utilidad: "El ser-útil (Zeugsein) del útil consiste en su utilidad (Dienlichkeit)" (Heidegger, 1935, p. 18). Es evidente que el martillar, o sea, el martillo en su verdad, en su ejecutarse como tal martillo, actuando, siendo martillo, nada tiene que ver con representarlo o pensarlo conceptualmente: "El martillar con el martillo no capta (erfaßt) este ente temáticamente (thematisch) como cosa que se presenta (vorkommendes Ding)" (Heidegger, 1927, § 15, p. 93). El ser del útil está en su uso, en lo que llama Heidegger $(1927, \S 15$, p. 96) su 'ser a la mano': "El 'ser a la mano' (Zuhandenheit) es la determinación ontológico-categorial del ente tal como es en sí”. Su verdad está en su ser-empleable, o sea, en nuestro vivirlo en su utilidad ejecutiva, de modo que el ser del martillo está en el martillar del martillo y 
el del zapato en el andar con él. Mientras los usamos, los vivimos y ellos están ejecutándose en acto, no reparamos en ellos. Sólo lo hacemos cuando se estropean y no cumplen correctamente su función. Entonces, descubrimos su "inempleabilidad (Unverwendbarkeit)" y el útil, afirma Heidegger (1927, § 16, p. 98), deja de ser útil, de "estar a la mano' y "salta a la vista", "llama la atención (auffällt)", de modo que ahora "lo inutilizable (Unbrauchbare) sólo está ahí (liegt nur da)", como una cosa, algo sólo representado que presenta un aspecto y no ya un útil servicial. Cuando nos dirigimos teóricamente a estos útiles y los representamos, ellos, en su ser-útil, en su verdad ejecutiva, ya no están ahí. La representación no puede representar la utilidad del útil, su servicio y acción ejecutiva.

Así, sobre una de las versiones de las conocidas botas pintadas por Van Gogh, escribe Heidegger (1935, p. 18) que "la campesina lleva las botas al campo. Sólo ahí las botas son lo que son (was sie sind). Son cuanto menos la campesina piensa (denkt) en las botas mientras trabaja, cuando ni siquiera las mira (anschaut) ni las siente (spürt)". Las botas son las botas cuando las usa la campesina, cuando ejecutan su servicialidad, cuando las vive, no cuando las representa. Por esto, añade Heidegger (1935, p. 18), "mientras sólo tengamos presente (vergegenwärtigen) un par de botas en general o veamos en el cuadro unas simples botas que están ahí vacías e inutilizadas (ungebrauchten), jamás experimentaremos (erfahren) lo que verdaderamente es el ser-útil del útil". Pero Heidegger da un paso más allá. En el cuadro de Van Gogh no hallamos la verdad del útil, pero la verdad de esas botas es otra cosa distinta. Esa verdad reúne tanto el mundo como la vida de la campesina, pero también a la tierra (Erde) que los acoge. Heidegger describe todos los rasgos que constituyen la verdad mundana, existencial y terrestre de aquellas botas, desde la fatiga del trabajo hasta el estremecimiento (Beben) por un próximo nacimiento y el temblor (Zittern) ante la amenaza de la muerte (Umdrohung des Todes), pasando por la soledad (Einsamkeit) del camino, la callada llamada de la tierra (verschwiegene Zuruf der Erde) y el temor por asegurarse el pan (Heidegger, 1935, p. 19). Aunque pueda parecer que todas estas cosas sólo podemos verlas en las botas del cuadro, porque la campesina se limita a usarlas, realmente la campesina, al quitárselas tras la fatiga del trabajo diario o al ponérselas al amanecer, las vive, sin reparar en ellas, sin saber nada de ellas, "sabe (wei $\beta$ ) todo eso sin contemplación ni consideración" (Heidegger, 1935 , p. 19). La campesina sabe la verdad de las botas sin tener que mirarlas ni reflexionar sobre ellas. Este mismo saber antepredicativo, no conceptual, es el que despliega la obra de arte de Van Gogh: "La obra de arte nos permite saber (gab zu wissen) lo que es verdaderamente un zapato" (Heidegger, 1935, p. 21).

Esto que pasa con una cosa, con un útil, pasa con el propio ser, con el hecho de ser. Igual que reparamos en el útil cuando deja de funcionar, es la muerte, que daña al ser y lo estropea, la que nos convoca a pensar en él. La conciencia de la muerte es la que nos apremia a reparar en el ser. Del mismo modo que la campesina sabe preconceptualmente la verdad de las botas, el Dasein sabe prerreflexivamente la verdad del ser. Es notorio que Heidegger (1927, § 4, p. 16) considera que "la comprensión del ser (Seinsverständnis) es una determinación de ser (Seinsbestimmtheit), o sea, una determinación ontológica, del Dasein". Pero esta comprensión del ser que caracteriza al Dasein es una "comprensión preontológica del ser (vorontologischen Seinsverständnisses)" o, dicho de otro modo, "la comprensión del ser que yace (liegende Seinsverständnis) en el Dasein se expresa (ausspricht) preontológicamente" (Heidegger, 1927, § 4, 42, pp. 18, 261). Esto significa que la comprensión del ser que define al Dasein es previa a la elaboración de una ontología conceptualmente desarrollada, es decir, una ontología entendida como "el explícito preguntar teórético (explizite theoretische Fragen) por el ser de los entes" (Heidegger, 1927, § 4, p. 16). En definitiva, es una comprensión preconceptual, antepredicativa, justo como aquel saber prerreflexivo de la campesina. Sein und Zeit es una ontología, o sea, el planteamiento de la pregunta por el ser, lo que equivale a 
radicalizar aquel saber preontológico llevándolo al plano predicativo, a conceptualizar aquella comprensión prerreflexiva: "La pregunta por el ser (Seinsfrage) no es sino la radicalización (Radikalisierung) de una tendencia ontológica (Seinstendenz) que pertenece esencialmente al Dasein, la comprensión preontológica del ser" (Heidegger, 1927, § 4, p. 20). Heidegger conceptualiza la ontología prerreflexiva de la campesina, reconquista en el plano de la reflexión aquel saber antepredicativo del ser que nos constituye a todos. Si Heidegger se apartó de este camino y llevó a cabo un viraje, la Kehre, es porque consideró que la fenomenología hermenéutica de Sein und Zeit no era la vía adecuada para afrontar el problema del ser y sí lo era el arte. Recordemos que fue el cuadro de Van Gogh el que nos hizo saber lo que es de verdad un zapato. Para Heidegger (1935, pp. 21s, 25), "el arte es el ponerse en obra de la verdad (Sich-ins-Werk-Setzen der Wahrheit)".

\section{EL PENSAR NO INTELECTUALISTA}

Si empleamos las categorías todavía en sentido metafísico-sustancialista entonces quien afirma la identidad no puede afirmar el devenir, porque el devenir implica esencialmente la diferencia. En efecto, el devenir es cambio, productor de diferencias que no repiten la identidad ya dada. La propia idea del devenir implica ya la diferencia. Por tanto, el antagonismo entre identidad y diferencia equivale a la oposición entre lo dinámico y lo idéntico. De aquí se desprende que la síntesis que buscamos se corresponde con la mediación entre identidad y devenir. Frente a la posición metafísico-sustancialista que de entrada comprende devenir e identidad como irreconciliables, lo que buscamos es incorporar el devenir en la identidad, o encajar la identidad en el devenir. Alojar el devenir en el corazon de la identidad es la forma de encajar la diferencia en la identidad. Sólo la superación de aquella metafísica de la sustancia permite la renovación de los conceptos de identidad y devenir y su consiguiente mediación. Sólo así se puede fusionar devenir e identidad y conciliar la metafísica del acto y la metafísica de la representación. Esta síntesis no puede justificarse si nos movemos exclusivamente en categorías estáticas. Es necesario introducir categorías dinámicas. Sólo la idea de proceso y devenir puede legitimar aquella mediación. La síntesis que buscamos entre cosa y proceso, representación y acto, coincide con la reunión entre identidad y diferencia o, lo que es lo mismo, entre devenir e identidad. Lo que pretendemos es la unificación de todas estas categorías sin jerarquías ni subordinaciones, sino más bien mediándose una con otra. No pueden ser comprendidas como meros contrarios sino que cada una se da en y con la otra, de modo que ninguna es sin la otra, pues sólo se definen en su mutua relación de oposición y enfrentamiento. Frente a la exclusión y a la elección entre representación/acto o identidad/diferencia, integración. Pero ¿cómo concebir esta mediación?, ¿cómo lograr que cada una sea también la otra?

La síntesis entre la identidad y el binomio devenir/diferencia se corresponde con la fusión entre aquellas dos grandes tradiciones metafísicas, la del acto y la de la representación, el platonismo y el aristotelismo. Ahora bien, y esto es fundamental para intentar responder a nuestra pregunta, reparemos en que estas síntesis equivalen también a otra, a la integración entre conciencia y devenir. No olvidemos el elemento moderno que trae consigo la metafísica de la representación: la conciencia. No es arbitrario añadir el ingrediente de la conciencia a la combinación entre identidad y devenir/diferencia, es una incorporación necesaria. La conciencia y su pensar han sido los conceptos básicos de la filosofía moderna. El poder concedido por Descartes al sujeto pensante evita el antiguo e ingenuo objetivismo que ignoraba el papel de la subjetividad, pero tengamos presente que esta conciencia cartesiana de carácter representacional ha sido el principal instrumento objetivador y cosificador. Lo que pretendemos es, asumido el papel decisivo de la 
conciencia y el pensamiento por Descartes, incorporarlo a la filosofía de la Tathandlung fichteana, que por su parte significa el triunfo del devenir y la libertad frente al estatismo dogmático y cosista. Esto supondría ya la conciliación de la metafísica del acto (Fichte) y de la representación (Descartes). Pero esta incorporación sólo es posible, primero, si se libera el descubrimiento moderno del pensar de su versión cartesiana, intelectualista y representacionalista/objetivadora, pues de otro modo sería imposible unirlo a su contrario, la filosofía dinamicista fichteana; y segundo, si esta pura actividad de Fichte llega a contener la reflexión y el saber de sí misma. Pero estas dos condiciones se resumen en una. Efectivamente, sólo quitándole al pensar cartesiano ese rasgo intelectualista de representación objetivadora, podrá unirlo a lo que no se deja objetivar ni representar, la actividad fichteana. A su vez, gracias a este novedoso pensar no intelectualista, podrá afirmar que la ejecutividad ya sí implica presencia para sí, reflexión, naturalmente una reflexión ya de índole no representacional, no objetivadora, sino real, vital, entitativa. El saber que implica este pensar es aquel que tengo en cualquier vivencia de aquello que vivo sin necesidad de realizar un acto intelectual de reflexión: cuando amo, sé que amo en tanto que vivo mi amor, sin necesidad de pensarlo intelectualmente con conceptos. No es un saber objetivador sino con valencia ontológica puesto que forma parte de la misma realidad que sabe y sobre la que se vuelca. Sólo mediante este saber entitativo o vital será posible fusionar la metafísica del acto con la de la representación.

\section{CONCLUSIÓN}

La clave del problema no es otra que introducir la conciencia en el devenir, incorporar la representación en acto. Para lograrlo, para anudar la metafísica de la representación y la del acto, frente a la interpretación cosista e intelectualista, se necesita esta conciencia no teorética/intelectualista que representa (sabe) el devenir (vivir) sin objetivarlo. El pensar de esta conciencia, lejos de ser algo meramente exterior al acto de vivir de carácter representativo/objetivador, forma parte de él, de manera que entonces ese pensar posee una naturaleza ontológica. Al pertenecer constitutivamente al devenir permite que éste se comprenda entitativamente y no intelectualmente. La ejecutividad entonces, el acto, contiene presencia para sí. Sólo esta ontologización y desintelectualización del pensar hace posible la incorporación de la conciencia pensante en el acto, que ahora sí puede llevar consigo la autoconciencia -ya no intelectual ni objetivadora. Una vez ontificado el pensamiento y liberado de su condición contemplativa y distante, representacionalista y objetivadora, puede incorporarse a la Tathandlung fichteana, la acción productiva. El núcleo de la cuestión es que el pensamiento deje atrás la estructura sujeto/objeto, de carácter visual, intelectual, objetivador, para que adopte una naturaleza más dinámico/entitativa y menos intelectualista, y erradique su tendencia objetivadora. El pensar entonces ya no es aquel pensar visualista/intelectualista, distante, que representa objetivando, propio del cartesianismo, sino que ahora tiene carácter ontológico/entitativo pues pertenece a la misma realidad que piensa (sujeto) y es pensada (objeto). Sólo esta conciencia no intelectualista, no representacionalista, posibilita una actividad, un devenir que incluye el pensar no objetivador. Esta es la única forma de responder al -en principio- irresoluble problema de la inobjetivabilidad del acto y, con ello, de superar la oposición entre la metafísica del acto y de la representación. El ejecutarse del devenir es irrepresentable como tal, inobjetivable, pero el pensar puede incorporarse al propio ejecutarse de forma constituyente, de manera que se da cuenta de sí en tanto se ejecuta, no conceptualmente en un segundo acto exterior. El pensar no objetiva el acto, forma parte de él. Sólo por ello, por sobrepasar la intelectualista filosofía de la representación objetivadora, se puede integrar devenir y conciencia, acto y representación. 


\section{REFERENCIAS}

DELEUZE, G. (1968), Différence et répétition, Paris: PUF.

DILTHEY, W. (1911), Die Typen der Weltanschauung und ihre Ausbildung in den metaphysischen Systemen, Gesammelte Schriften, Band 8: Weltanschauungslehre, Stuttgart: Vandenhoeck

32 \& Ruprecht, 1977. . Band VI, Berlin: De Gruyter, 1971.

FICHTE, J. G. (1794-1802), Grundlage der gesammten Wissenschaftslehre, FW, Band I, 1971.

FICHTE, J. G. (1797a), Zweite Einleitung in die Wissenschaftslehre, FW, Band I.

FICHTE, J. G. (1797b), Versuch einer neuen Darstellung der Wissenschaftslehre, FW, Band I.

FICHTE, J. G. (1800), Die Bestimmung des Menschen, FW, Band II, 1971.

FICHTE, J. G. (1805), Über das Wesen des Gelehrten, und seine Erscheinungen im Gebiete der Freiheit, $F W$, Band VI.

HEIDEGGER, M. (1927), Sein und Zeit, Gesamtausgabe, Band 2, Frankfurt a. M: Klostermann, 1977.

HEIDEGGER, M. (1931-40), Platons Lehre von der Wahrheit, Wegmarken, Ga, Band 9, 1976.

HEIDEGGER, M. (1935), Der Ursprung des Kunstwerkes, Holzwege, Ga, Band 5, 1977.

HEIDEGGER, M. (1935-36), Die Frage nach dem Ding, Ga, Band 41, 1984.

HEIDEGGER, M. (1941), Die Metaphysik als Geschichte des Seins, Nietzsche, Ga, Band 6.2, 1997.

HEIMSOETH, H. (1922), Sein und Lebendigkeit, Die sechs großen Themen der abendländischen Metaphysik und der Ausgang des Mittelalters, Stuttgart: Kohlhammer, 1965, pp. 131-171.

HENRY, M. (1985), La généalogie de la psychanalyse. Le commencement perdu, Paris: PUF.

HENRY, M. (2012), Heidegger, Descartes, Nietzsche: Schopenhauer et le 'courant souterrain' de la metaphysique, Les Études Philosophiques, n 3, pp. 307-317.

HUSSERL, E. (1912), Ideen zu einer reinen Phänomenologie und phänomenologischen Philosophie, Husserliana III/1, Den Haag: Martinus Nijhoff, 1976.

NIETZSCHE, F. (1885-86), Nachgelassene Fragmente, Kritische Studienausgabe, Band 12, München, De Gruyter, 1980.

NIETZSCHE, F. (1886-87), Nachgelassene Fragmente, KSA, Band 12.

RICOEUR, P. (1950), Philosophie de la volonté. Tome I: Le volontaire et l'involontaire, Paris: Aubier, 1988.

SCHOPENHAUER, A. (1819), Die Welt als Wille und Vorstellung, Sämtliche Werke, Band I, Frankfurt a. M: Suhrkamp, 1986.

SPINOZA, B. (1677), Ethica ordine geometrico demonstrata, Spinoza Opera, II, Heidelberg: Carl Winter, 1972.

\section{Notas}

1 Fichte (1800, p. 263) lleva esta preminencia de la actividad al terreno epistemológico, de manera que "no actuamos (handeln) porque conocemos (erkennen) sino que conocemos porque estamos determinados (bestimmt) a actuar (zu handeln). La razón práctica (praktische Vernunft) es la raíz (Wurzel) de toda razón".

2 Desde la perspectiva aristotélico/dinámica del ser como enérgeia, el ente será concebido, según

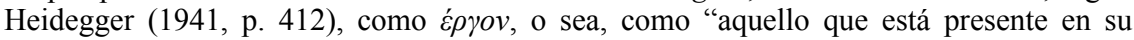
producción (Hergestelltheit Anwesende)", como lo "efectuado en el efectuar (im Wirken Gewirkte), lo realizado en el hacer (im Tun Ge-leistete)".

3 En otro lugar, Henry $(1985$, p. 8) ha escrito que "es Schopenhauer quien pone un final brutal (terme brutal) al reino de la metafísica de la representación al declarar que ésta no muestra en ella nada que pueda pretender la condición de ser real o de existencia verdadera (véritable)".

4 Fichte (1794-1802, p. 188) confirma que "el yo, tal como aquí es considerado, es simplemente lo contrario del no-yo y nada más; y el no-yo (Nicht-Ich) es lo contrario del yo (Gegenteil des Ich) y nada más". 